\title{
Use Big Data Thinking in the Cultivation of Police Intelligence Ability
}

\author{
Jianying Xiong \\ Security Management Department of JiangXi Police College, Jiangxi Police Institute, Nanchang 330013, China
}

\begin{abstract}
The public security personnel need a higher ability for the intelligence analysis due to application of big data policing. Combined with the application environment of big data policing, it analyzes the problems existing in the cultivation of students' information literacy in Police Colleges and universities, and expounds the application of big data thinking in the public security personnel intelligence judgment. It analyzes the development of the research paradigm of information processing in public security department, and established the model of intelligence judgment with big data thinking, which is on the basis of the existing intelligence analysis model. Finally, it shows how to implement the integration of large data thinking in intelligence analysis through a specific case analysis of criminal, and provides a practice teaching method for training intelligence quality of public security personnel in the information age.
\end{abstract}

Keywords- police intelligence analysis; big data thinking; intelligence quality training

\section{INTRODUCTION}

The era of big data has brought numerous opportunities for the industry. For the public security system, all the social information is the source of public security intelligence information. The usage of this information will bring a lot of convenience for access to public security information [1]. In 2003 our country put forward "intelligence led policing" strategy. The era of big data will inevitably lead to the change of intelligence work of police, and to promote police intelligence work into the big data stage. It is an important way to improve the ability of police intelligence analysis to integrate the methods and techniques of big data [2]. In the past environment of "intelligence led policing" has revealed the intelligence personnel is with a limited quantity, and it is largely restricted to further improve the level of police intelligence work.

Now with the advent of the era of big data, policing information is no longer to smaller, and fewer types of data, but pay more attention to the utilization of the big data. So it can promote the development of big data policing, and expand the scope of services. With the development of big data police, it has put forward higher requirements for the intelligence quality of police officers. The work of the intelligence personnel police officers is to extract valuable information from the massive basic information [3]. The ability of analysis and judgment of information determines the quality of intelligence products to a large extent, and determines the level of the actual use of information products and services. Therefore, the students in public security should strengthen the ability of intelligence analysis and judgment as core ability.

\section{RELATED WORK}

Chinese People's Public Security University has been approved to establish public security information science for undergraduate education for the first time in March 2005. Now there are more than ten public security colleges have set up the related public security intelligence science. With the development of information technology, the public security organs face the challenges of information technology reform in the process of social management, combat and prevention of crime. With regard to the training of public security information, many scholars are thinking about it [4]. Crispino supported that it only through education to solve the shortcomings in police intelligence management, and to establish course to improve police officers' intelligence awareness [5]. CPKN (the Canadian police knowledge network) provide free platform for police officers, the platform cooperated with London police to develop online courses [6]. Through a sample survey of 40 Hongkong police officers of the information search behavior, Chan found that the respondents are lack of effective information search, and they generally use only simple retrieval technology. The study recommended that the police need to use library information resources prior to the entry [7], and strengthen the information literacy education. according to the Taiwan Police College of information online learning platform, Wang explore the information literacy has 6 dimensions, including seeking information ability, the ability to get the information and use of information capabilities, comprehensive information, assessment information and information sharing capabilities.

The application of big data has been successfully applied in the field of public security intelligence, in various states in the United States [8]. Compared with foreign countries, our country's public security departments have the largest number of personal information database. Processing the large information in the past, the police will cost few days, a few weeks or months. But if use special police big data system, it may be done by a few hours, which will undoubtedly increase the work efficiency. So the application of big data has an impact on policing [9]. In the era of the big data, police officers need to become digital personnel in order to meet the needs of the development of modern police. 


\section{Big Data Thinking Model of Public Security INTELLIGENCE ANALYSIS}

\section{A. Public Security Intelligence Work}

There are two development directions of public security information. The first is the electronic policing; the other is the information platform. The former is for the management of services, and focusing on the reconstruction of the police process. The latter is oriented to prevent, combat, and control crime, it also beneficial to decision support [10]. Through data mining, more information will be discovered to help the public security make scientific decision. Intelligence work has entered into the big data paradigm the stage as shown in the figure. It should use big data thinking to improve the public security intelligence information work.

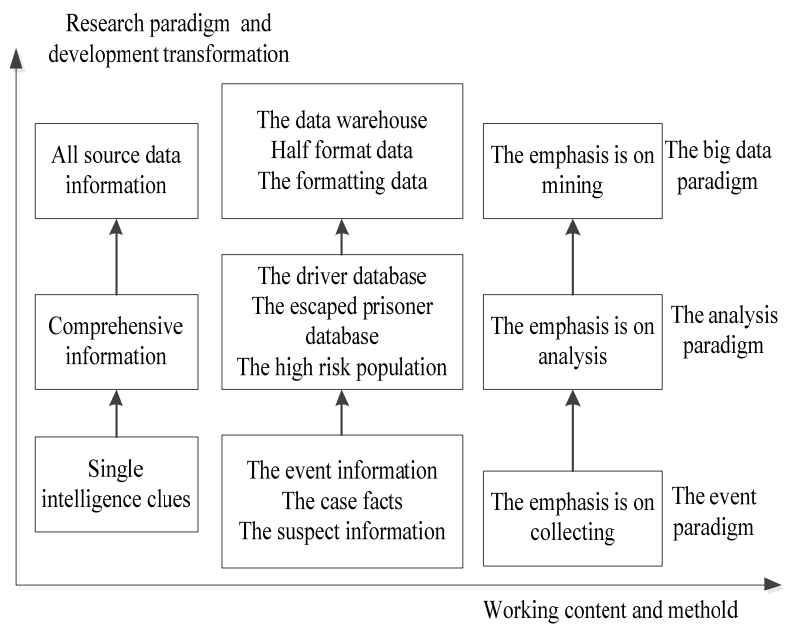

FIGURE I. EVOLUTION OF PUBLIC SECURITY INTELLIGENCE RESEARCH LEVEL AND PARADIGM

\section{B. Big Data Thinking in Public Security Intelligence}

Big data not only changed people's way of life and work, but the key is that it changed the way think. First, for the study of public security intelligence, intelligence research model use all source data instead of a sample case. All the data is information: time, place, vehicles, personnel, transportation and so on are all information resources. Second, there is an implied relationship between the different data, which reveals a relation between these hidden rules of crime. For the public security intelligence work, the perpetrators of criminal acts and his life behavior are related, they are mutually confirmed. So the causal relationship is related, we not only investigate the causal relationship between things, but by the relevant things to predict [11].

Intelligence research on big data shows that the objective world paradigm is interrelated and dialectical unity. It has used the method of connection and unified intelligence to study problems based on the relationship of system.
C. Big Data Thinking Model of Intelligence Analysis

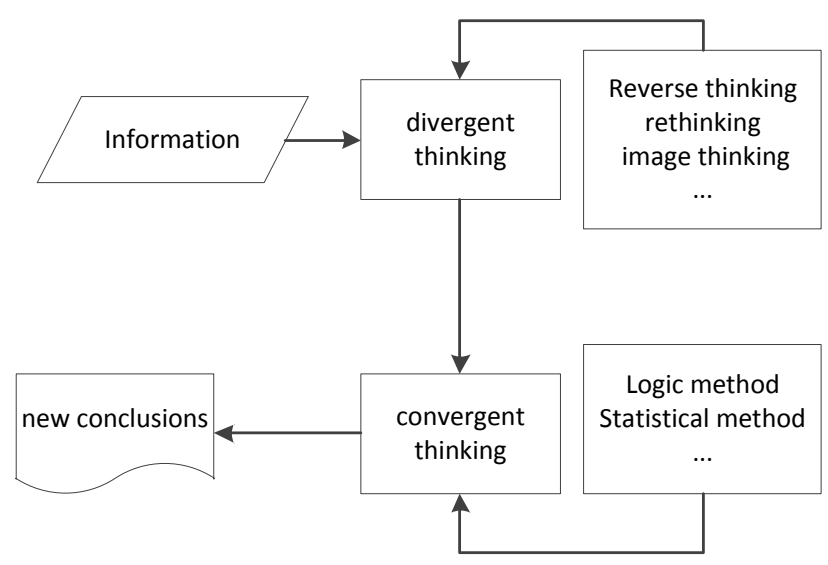

FIGURE II. TRADITIONAL INTELLIGENCE ANALYSIS THINKING MODEL

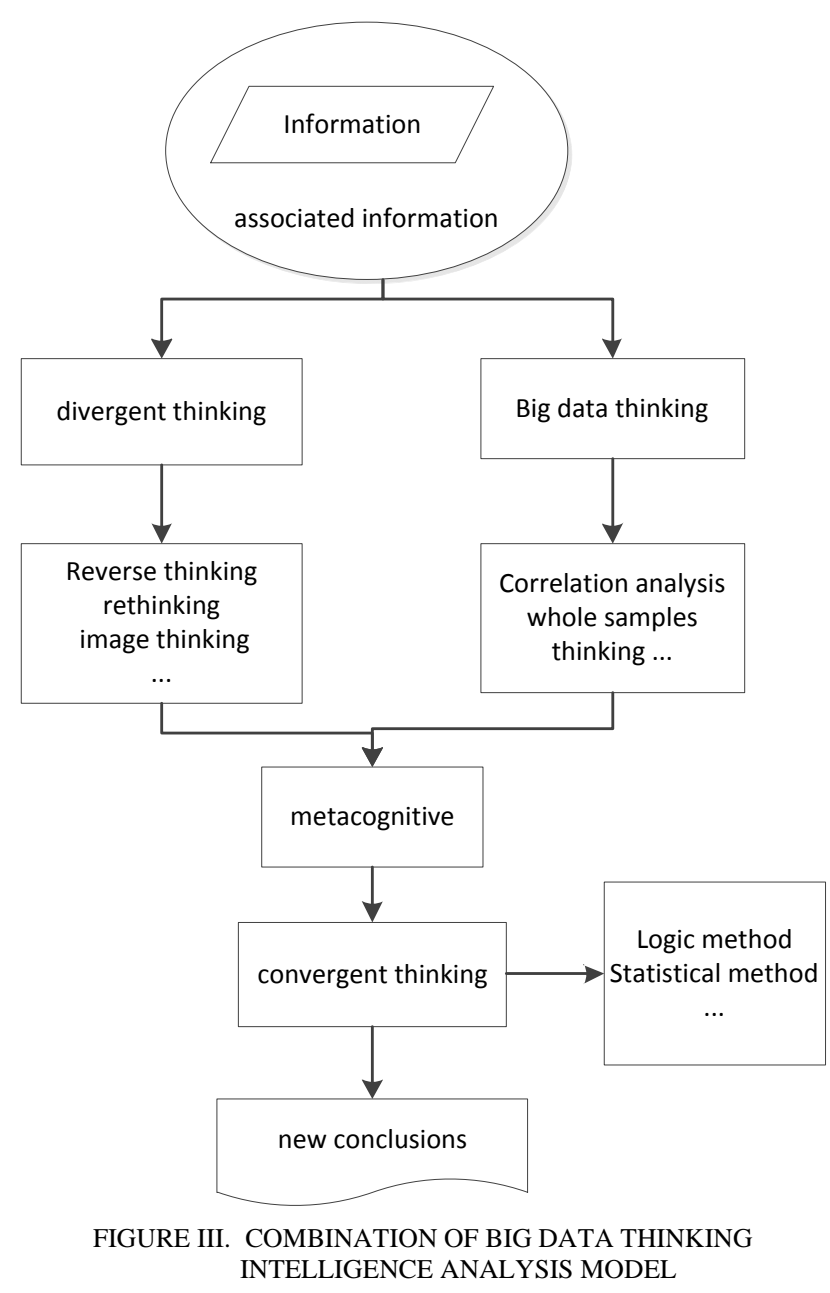

Intelligence analysis is not only related to the collected information, but also related to people's thinking. Intelligence analysts not only to sort out the information, but to analyze information from a large amount of information are more important. The logical thinking intelligence not only needs 
rigorous, convergence, but also needs more flexible, divergent, as shown in Figure II.

In big data era, the core of computing model has also undergone a shift from the process into data. Big data thinking is characterized by full sample data thinking, correlation thinking. The vast amount of data is also beyond the limits of human information processing, and need to use modern means of information. Big data thinking can promote people's inspiration, image, divergence and logic to help analysts generate innovative thinking. So in the mode of thinking, people's thinking will be combined with the machine thinking, interaction, get the different possibilities of the meta cognition, and then induction by the convergence as in Figure III.

\section{Intelligence AnAlysis CASEs By Big Data THINKING}

\section{A. Case Content}

It is a vicious injury event.

\section{B. Background}

The victim's social relationship is complex; it is difficult to determine the suspect; the first scene and the second scene are far apart.

\section{Artificial Thinking}

First of all, we should to guide students to reason crime process by reverse reasoning based on criminal behavior characteristics in intelligence analysis. A conclusion of the suspect is bound to have a means of transport. Because there are a lot of bayonet in this line, and there are a lot of vehicle surveillance video, we can suggest the police officers to take the relevant vehicle information as a breakthrough to detect the case.

\section{Big data Thinking}

Guide the student to put the victim as the center, and to collect all related information to the victim, such as person, car, money flow, virtual account information. All the related date will make Correlation analysis by the big data analysis software. More visual information will be obtained, and used to guide investigation

\section{E. Big data Collection}

Information resources involved of big data is as shown in the figure, a collection of big data information will been done.

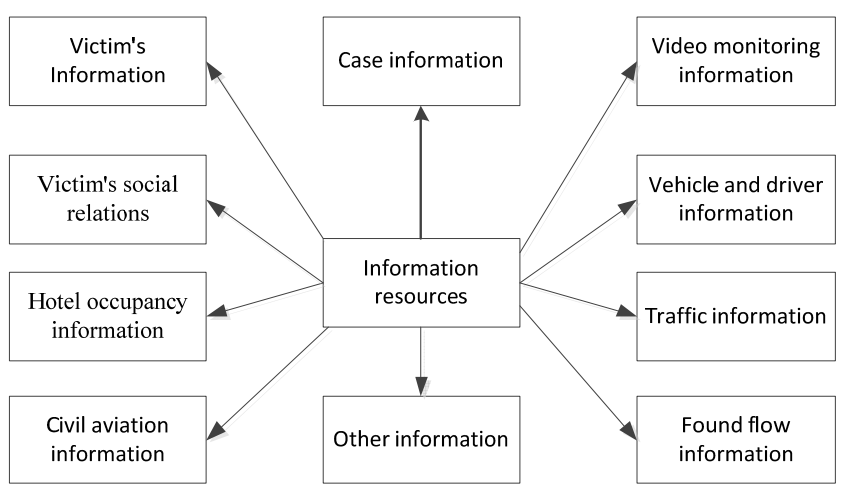

FIGURE IV. PUBLIC SECURITY INFORMATION RESOURCES IN THE ERA OF BIG DATA

- Get the victim's social relations: relatives, recent contacts.

- Get the recent activities of the victim track: hotel occupancy information, civil aviation information, traffic information.

- Get Victim fund account information.

- Get victim network social information.

- Get information about the vehicle.

- Get vehicle information of the second crime scene near the highway toll station.

- Get the video surveillance information for all the two crime scenes.

\section{F. Intelligence Analysis Model}

The big data model for criminal intelligence analysis is mainly reflected in the relationship between the association of the big data, including the relationship between man and man, the relationship between man and things, etc.. In the figure, the Investigation path consisting of marked gray background data is the key path of intelligence research, which is relatively easy and direct access to information, and carries out investigation. But if it cannot access to valuable information, more data can be extracted from big data. For example, using the traffic information, lodging information, network virtual information, and cash flow information, to expand people set circle of victim. Combined with the analysis of time, space, means of crime behavior, characteristics of the process, classify the case, use a big data mining thinking to mine suspicious information, determine the direction of the investigation. 


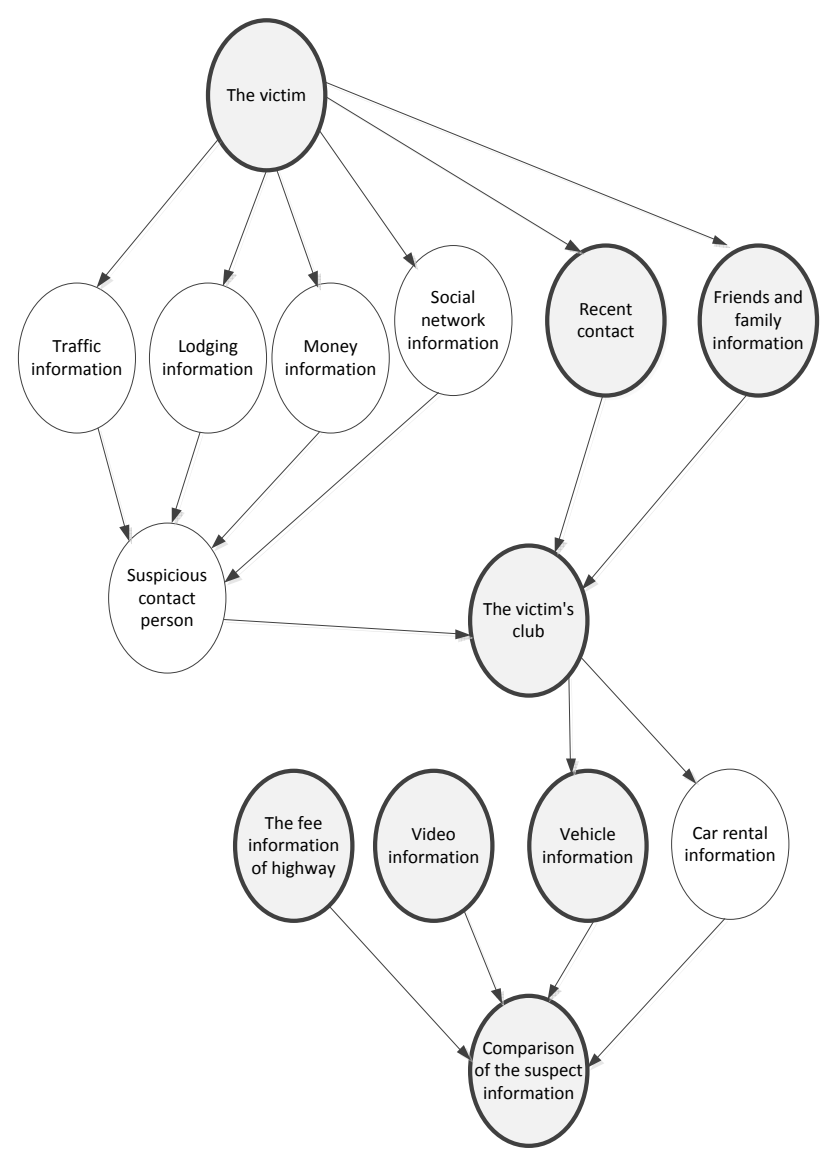

FIGURE V. INTELLIGENCE INVESTIGATION PATH IN BIG DATA ERA

\section{CONCLUSION}

As a social science, the public security information science has changed a lot, such as the research content, the way of work and the thinking mechanism. With the development of information technology, it is an important way to improve the ability of public security information analysis by integrating the methods and techniques of big data. Public security information is an important foundation to support the police activities and decision-making. The research of public security information is changing from simple to complex, from single to multiple, from single clue to data intensive paradigm. The research on the application of big data thinking in the public security intelligence analysis is beneficial to the development of police intelligence education.

\section{ACKNOWLEDGMENT}

This research was financially supported by Soft Science Project (NO. 20161BBA10037) of Department of science in Jiangxi province, and Education Reform Project (NO. JXJG15-19-1) of Department of Education in Jiangxi province.

\section{REFERENCES}

[1] Sanders. C. B.. T. Christensen. and C. Weston. "Constructing crime in a database: Big data and the mangle of social problems work." Qualitative
Sociology Review 11.2(2015):180-194.

[2] Costanzo, Pietro, F. D’Onofrio, and J. Friedl. Chapter 16 - Big Data and the Italian Legal Framework: Opbortunities for Police Forces. Application of Big Data for National Security. Elsevier Inc. 2015:238-249.

[3] Peng. Zhihui. "On Ontimization of Police Intelligence Process under Big Data Environment." Journal of Intelligence (2016).35(4):15-20

[4] Stanier, Ian. Enhancing Intelligence-Led Policing: Law Enforcement's Big Data Revolution. Big Data Challenges. Macmillan Education UK, 2016.5:97-113.

[5] Crispino, Frank, et al. "Education and training in forensic intelligence: a new challenge." Australian Journal of Forensic Sciences 47.1(2014):112.

[6] Jackson C. Evaluation Report: Police Information Portal Learning and Evaluation Event. Learning \& Evaluation Report, 2011.

[7] Nga, Kwai, et al. "Information Seeking Behavior of Police Officers in Hong Kong : An Exploratory Study." (2010):11-12.

[8] Manrique, Pedro, et al. "Context matters: Improving the uses of big data for forecasting civil unrest: Emerging phenomena and big data." IEEE International Conference on Intelligence and Security Informatics IEEE, 2013:169-172.

[9] Shen. Liangzhong. et al. "The Annlication Research of OLAP in Police Intelligence Decision System." Procedia Engineering 29(2012):397402.

[10] Zhang, Leihua, and S. P. Academy. "The Paradigm Change of Public Securitv Intelligence Studies from the Perspective of "Big Data"." Journal of Intelligence (2015).

[11] Shen, Yun, and O. Thonnard. "MR-TRIAGE: Scalable multi-criteria clustering for big data security intelligence applications." IEEE International Conference on Big Data IEEE, 2014:627-635. 